\title{
Thermodynamic Studies on the Glass Transition and the Glassy State of Polymers. I. Pressure Dependence of the Glass Transition Temperature and Its Relation to Other Thermodynamic Properties of Polystyrene
}

\author{
Shoji Ichinara*, Akihiko Komatsu**, Yoshiharu Tsujita, \\ Takuhei Nose, and Toshio Hata \\ Department of Polymer Chemistry, Tokyo Institute of Technology, \\ Tokyo, Japan.
}

(Received March 8, 1971)

\begin{abstract}
The pressure dependence of the glass transition temperature, $T_{\mathrm{g}}$, and the coefficients of thermal expansion, $\alpha$, and the compressibility, $\beta$, of polystyrene were measured. For the same sample, DSC measurement was also carried out, to obtain specific heat, $C_{p}$. From the results, it was confirmed that the relation $\left(\partial T_{\mathrm{g}} / \partial P\right) \cong$ $T V \Delta \alpha / \Delta C_{p}<\Delta \beta / \Delta \alpha$ was valid, in accordance with our theory based on a hole model for polymer liquids and glasses with an assumption of iso-configurational entropy at $T_{\mathrm{g}}$. Changes of specific heats at $T_{\mathrm{g}}$ associated with intrasegmental interactions and intersegmental ones were calculated separately by the use of the theory, and $\Delta C_{p}$ intra $=0.041$ and $\Delta C_{p^{\text {inter }}}=0.036 \mathrm{cal} / \mathrm{gK}$ were obatined.

KEY WORDS , Polystyrene / Glass Transition / Glassy State / Pressure

Dependence / Configurational Entropy/Specific Heat / Specific

Volume / Densified Glass /
\end{abstract}

It is well known that the glassy state is a thermodynamically non-equilibrium state and the glass transition is not a thermodynamic transition of the second order. However, because of this fact, it is all the more interesting to study the glassy state thermodynamically, comparing it with the crystalline or the liquid states, which is not impossible, because the glassy state can be regarded as a frozen state in a usual experimental time scale. From this point of view, many efforts have been devoted to the possibility of thermodynamic analysis of the glassy state and the glass transition temperature $T_{\mathrm{g}}$, giving a number of interesting results. As one such result, the following relation has been discovered, ${ }^{1-3}$

$$
\left(\frac{\partial T_{\mathrm{g}}}{\partial P}\right) \cong \frac{T V \Delta \alpha}{\Delta C_{p}}<\frac{\Delta \beta}{\Delta \alpha}
$$

* Present Address: Plastics Research Laboratory, Mitsubishi Petrochemical Co., Yokkaichi, Mie, Japan.

* Present Address: Showa Denko Co., Tamagawa, Ohta-ku, Tokyo, Japan. where $T, V$, and $P$ are absolute temperature, volume, and pressure, and $\Delta \alpha, \Delta C_{p}$, and $\Delta \beta$ are the differences in expansion coefficient, specific heat and compressibility between the liquid and glassy states at $T_{\mathrm{g}}$ respectively. Another important result is that one can obtain a glass having high density, the so-called densified glass, by glass formation under high pressure..$^{3-5}$

On the other hand, theoretical considerations about these facts have recently been made by $\mathrm{Nose}^{6}$ on the basis of a hole model for polymer liquids and glasses. He deduced a conclusion, in accordance with Goldstein ${ }^{7}$ that the glass transition occurs at a state of iso-configurational entropy or energy within a substance, and derived eq 1 theoretically. Further he predicted that densified glasses should have almost the same enthalpy in the glassy state.

In the present study we will examine the above theory, particularly concerning the relationships between $\left(\partial T_{\mathrm{g}} / \partial P\right), T V \Delta \alpha / \Delta C_{p}$ and $\Delta \beta / \Delta \alpha$ experimentally, because experimental values necessary to examine eq 1 have not yet been made by the 
Thermodynamic Studies on the Glass Transition and the Glassy State of Polymers. I.

other research workers for the same samples, but only collected data of $C_{p}$ and other values from $P-V-T$ relations which were published independently by the different authors have been used for the discussion.

\section{EXPERIMENTAL}

\section{Sample}

Commercial atactic polystyrene (Copal, Japan Olefine Co., Ltd.) was used as starting material. The material was purified by reprecipitation with acetone- $n$-hexane mixture. After drying for 3 day at room temperature and for $3 \mathrm{hr}$ at $60^{\circ} \mathrm{C}$ in a vacuum oven, the obtained powder was heated in a glass tube under vacuum gradually to $200^{\circ} \mathrm{C}$ to produce a block sample. The intrinsic viscosity $[\eta]$ of the sample in toluene at $30^{\circ} \mathrm{C}$ after these treatments was $0.857 \mathrm{dl} / \mathrm{g}$ and the molecular weight was calculated as $2.7 \times 10^{5}$ by use $^{8}$ of $[\eta]=3.7 \times 10^{-4} M^{0.62}$. Test pieces for following experiments were provided from this block sample.

\section{Experimental Method}

$P-V-T$ Relation. A block diagram of the pressure apparatus used is shown in Figure 1. The pressure vessel is about $60 \mathrm{~cm} \times 14 \mathrm{~cm} \phi$ in space size and is equipped with two windows

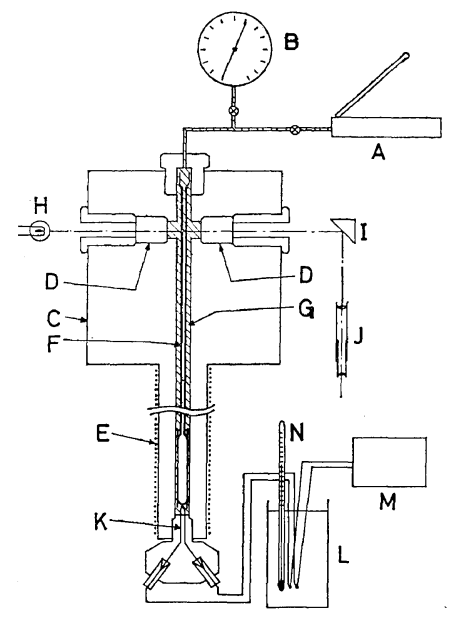

Figure 1. Apparatus for dilatometry under pressure: A, hand pump; B, $1400 \mathrm{~kg} / \mathrm{cm}^{2}$ Heise gauge; $\mathrm{C}$, presure vessel; D, windows; $\mathrm{E}$, heater, F, dilatometer; G, silicone oil; H, light source; I, prism; J, cathetometer; $\mathbf{K}$, thermocouple; $\mathrm{L}$, thermostat; $\mathrm{M}$, microvoltmeter; $\mathrm{N}$, thermometer. of pyrex glasss of $17 \mathrm{~mm} \phi$. An ordinary dilatometer is put in the vessel filled with silicone oil, and a change of volume, that is a change of mercury height with pressure or temperature is measured directly through these windows. In return for the advantage of direct measurement, the observable height as well as the applied pressure is restricted to a rather small range because of the limited length and strength of the glass windows. Detailed description of the pressure vessel and on the procedure of measurement will soon appear elsewhere. Care was taken to keep the vessel at uniformly constant temperature and also to measure the temperature with the same precision as pressure.

Measurements of $V-T$ relation were carried out under pressures of $150,300,450$, and 600 $\mathrm{kg} \mathrm{cm}^{-2}$. After attaining an equilibrium in the liquid state under a given pressure, temperature was decreased at the cooling rate of $1{ }^{\circ} \mathrm{C} / 3 \mathrm{~min}$, while the pressure was kept constant with a hand pump. At $30^{\circ} \mathrm{C}$ the pressure was released. Then densified glass was obtained. For the measurements of the $V-T$ relation under atmospheric pressure an ordinary dilatometer was used. Densities of these samples were measured by the flotation method in aqueous solutions of $\mathrm{CaCl}_{2}$ at $30^{\circ} \mathrm{C}$. Obtained values were averaged for $7-8$ experiments excluding abnormal ones.

Compressibility of a nondensified sample was measured by the isothermal compressions at different temperatures independent of the abovedescribed experiments.

Specific Heat. The apparatus used for specificheat measurements was a differential scanning calorimeter manufactured by the Perkin-Elmer Corporation, Model DSC-1. The programmed temperature $\theta$ read from the instrument dial was calibrated by the melting temperatures of standard substances such as Gelium, Indium, Tin, Bismus, and Lead, each having purity in the range of $99.99-99.999 \%$. Melting temperatures read out from recorded thermograms scattered within $\pm 0.2 \mathrm{~K}$, and $\theta$ calculated by the quadratic equation relating $\theta$ to $T$, which was obtained by the method of the least squares, had decrepancies within $\pm 0.2 \mathrm{~K}$ from real temperatures. Therefore the accuracy of the corrected temperature was $\pm 0.4 \mathrm{~K}$. 
Measurements were conducted according to the reported procedures ${ }^{9}$ with scanning interval of $85^{\circ} \mathrm{C}$. Scanning speed and the sensitivity setting used were $8^{\circ} \mathrm{C} / \mathrm{min}$ and $4 \mathrm{mcal} / \mathrm{sec}$ respectively. Specific heats of samples were calculated by the relationship;

$$
C_{p}=\frac{l}{m} \times \frac{m_{\mathrm{s}} C_{\mathrm{s}}}{l_{\mathrm{s}}}
$$

where $C_{p}, l$, and $m$ are specific heat, chartrecorder displacement, and weight of the sample, and $C_{\mathrm{s}}, l_{\mathrm{s}}$, and $m_{\mathrm{s}}$ correspondingly refer to the standard material (synthetic sapphire ${ }^{10}$ ).

The observed values of specific heat of polystyrene were found to scatter within about $\pm 2.5 \%$ for ten time experiments. Thereafter measurements were repeated three times for each sample and the obtained values were averaged.

\section{RESULTS}

Experimental values of specific volume $v s$. temperature under various pressures are shown

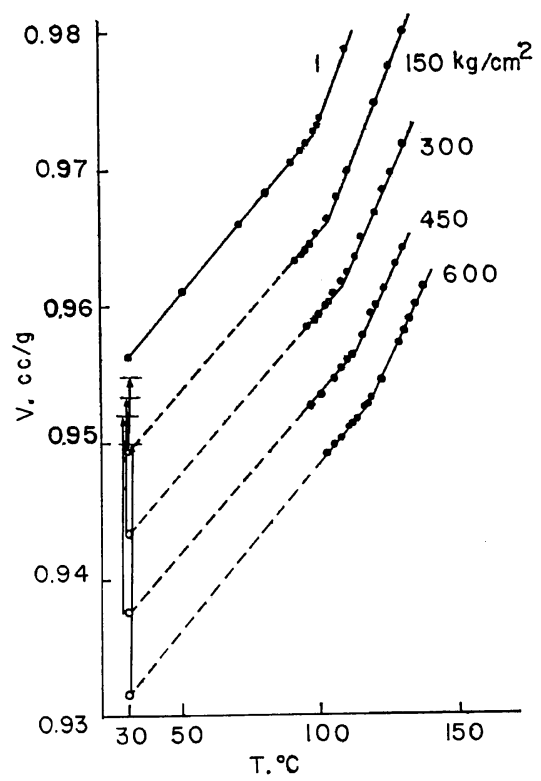

Figure 2. Specific volumes under various pressures cooled at $1{ }^{\circ} \mathrm{C} / 3 \mathrm{~min}$ plotted against temperature: solid lines and circles, observed; $\bigcirc$, calculated from specific volumes at $30^{\circ} \mathrm{C}$ under $1 \mathrm{~atm}$; arrow, volume changes when the presure is released at $30^{\circ} \mathrm{C}$. in Figure 2 by solid circles and lines. For the reason described above, the experimental values for densified glasses were not sufficient to determine the glass transition temperatures unambiguously. However, since we have the exact value of the specific volume at $30^{\circ} \mathrm{C}$ under atmospheric pressure for each densified glass as shown in the figure, we can calculate the specific volume at $30^{\circ} \mathrm{C}$ under given pressure with the use of compressibility data. These calculated values are shown by open circles in Figure 2 . It is clearly seen that these points can be connected with the experimental values for each pressure by the straight lines (dotted). The glass transition temperature was determined as the intercept of this line and the $V-T$ line of the liquid state.

The glass transition temperatures $T_{\mathrm{g}}$ thus obtained are plotted against pressures in Figure 3 by open circles. The line segments show their possible ranges according to the extrapolation of experimental values. The glass transition temperature increases linearly with the increase of pressure. From Figure 3, $\left(\partial T_{\mathrm{g}} / \partial P\right)$ was estimated to be $3.2 \times 10^{-2} \mathrm{~K} /\left(\mathrm{kg} \mathrm{cm}^{-2}\right)$.

Specific volume of the densified glass decreases with the increase of applied pressure. The magnitude of densification can be expressed by

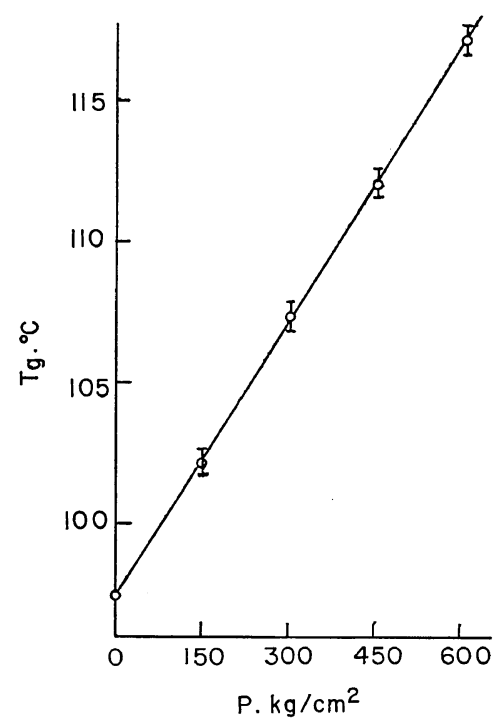

Figure 3. $T_{\mathrm{g}}$ of polystyrene cooled at $1^{\circ} \mathrm{C} / 3 \mathrm{~min}$ under various pressures. 
Thermodynamic Studies on the Glass Transition and the Glassy State of Polymers. I.

the following quatities

$$
\alpha^{\prime}=\frac{-1}{V_{\mathrm{s}}}\left(\frac{\partial V_{\mathrm{s}}}{\partial T_{\mathrm{g}}}\right) \quad \beta^{\prime}=\frac{-1}{V_{\mathrm{s}}}\left(\frac{\partial V_{\mathrm{s}}}{\partial P_{\mathrm{g}}}\right)
$$

where $V_{\mathrm{S}}$ is the volume at a certain temperature under atmospheric pressure of the glass formed at $T_{\mathrm{g}}$ and $P_{\mathrm{g}}$. In this study $\alpha^{\prime}=3.2_{5} \times 10^{-4} \mathrm{~K}^{-1}$ and $\beta^{\prime}=1.0_{5} \times 10^{-5}\left(\mathrm{~kg} / \mathrm{cm}^{2}\right)^{-1}$ were obtained at $30^{\circ} \mathrm{C}$.

Figure 4 shows compressibility, $\beta$, vs. temperature curve at atmospheric pressure. From the figures, $\Delta \beta$ at $97.4^{\circ} \mathrm{C}$, which is $T_{\mathrm{g}}$ under atmospheric pressure cooled at $1{ }^{\circ} \mathrm{C} / 3 \mathrm{~min}$, is estimated as $\Delta \beta=2.2_{8} \times 10^{-5}\left(\mathrm{~kg} / \mathrm{cm}^{2}\right)^{-1}$. From

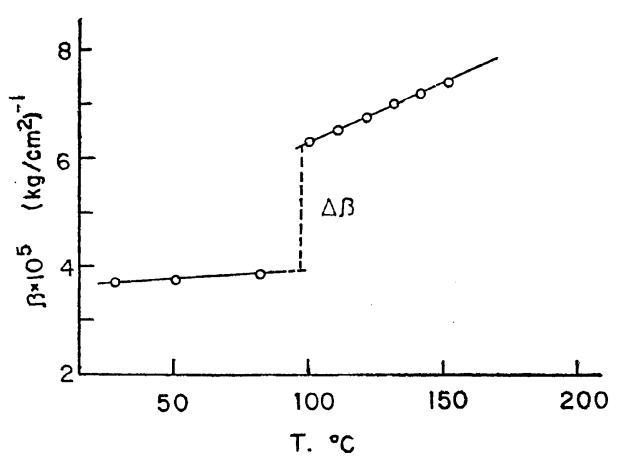

Figure 4. Compressibilty $\beta$ at atomospheric pressure plotted against temperature and $\Delta \beta$.

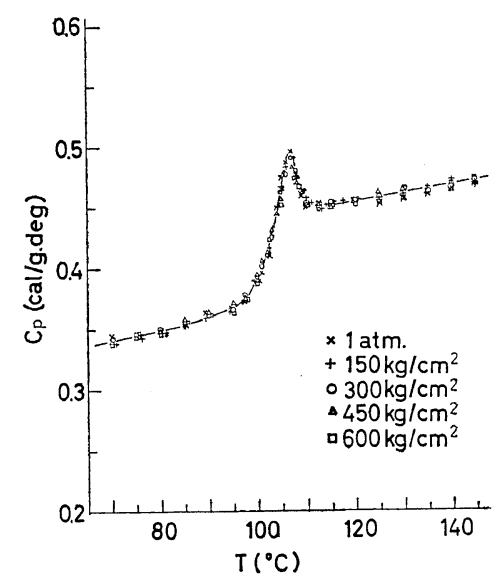

Figure 5. Specific heats of densified glasses of polystyrene measured with DSC using the heating rate of $8{ }^{\circ} \mathrm{C} / \mathrm{min}$. Polystyrene cooled beforehand at $1{ }^{\circ} \mathrm{C} / 3 \mathrm{~min}$ under $1 \mathrm{~atm}(\times), 150 \mathrm{~kg} / \mathrm{cm}^{2}(+), 300$ $\mathrm{kg} / \mathrm{cm}^{2}(\bigcirc), 450 \mathrm{~kg} / \mathrm{cm}^{2}(\triangle)$, and $600 \mathrm{~kg} / \mathrm{cm}^{2}(\square)$.
Figure 2 we also obtain $\Delta \alpha=3.1_{2} \times 10^{-4} \mathrm{~K}^{-1}$ under $1 \mathrm{~atm}$.

Results of specific-heat measurements are quite interesting as are shown in Figure 5. Inspite of the fact that the densified glasses were formed under different pressures and have different specific volumes as shown in Figure 2, the behavior of specific heat against temperature was almost the same, showing that densified glasses have almost the same enthalpy at least in the glass-forming conditions of this study. The difference of specific heats, $\Delta C_{p}$, between the liquid and glassy states was $0.077 \mathrm{cal} / \mathrm{g} \mathrm{K}$ at $97.4^{\circ} \mathrm{C}$. This value was obtained by averaging $C_{p}$ values from DSC measurements of twenty times.

\section{DISCUSSION}

First we recall some important formulae derived by Nose $^{6}$ concerning the pressure dependence of the glass transition temperature. The theory is developed from the hole theory for polymer liquids and glasses.

Defining the configurational entropy $S^{\mathrm{c}}$ as the entropy which is frozen in the glassy state, we have

$$
\left(\frac{\partial T_{\mathrm{g}}}{\partial P}\right)=\frac{T V \Delta \alpha}{\Delta C_{p}-T\left(\partial S^{\mathrm{c}} / \partial T\right)_{T_{\mathrm{g}}}}
$$

where the symbol $(\partial X / \partial Y)_{T_{\mathrm{g}}}$ denotes the change in $X$ with $Y$ along $T_{\mathrm{g}}$. We also have another expression for the pressure dependence of the glass transition temperature as

$$
\left(\frac{\partial T_{\underline{g}}}{\partial P}\right)=\frac{\Delta \beta}{\Delta \alpha+\alpha^{\prime}}=\frac{\left(\Delta \beta-\beta^{\prime}\right)}{\Delta \alpha}
$$

where

and

$$
\alpha^{\prime}=-\tilde{V}^{-1}(\partial \tilde{V} / \partial T)_{T_{\mathrm{g}}}
$$

$$
\beta^{\prime}=-\tilde{V}^{-1}(\partial \tilde{V} / \partial P)_{T_{g}}
$$

In eq $6, \tilde{V}$ is the reduced volume defined by $\tilde{V} \equiv V / V^{*}$ where $V^{*}$ is the cell volume. From the assumption involved in the theory, $\alpha^{\prime}$ and $\beta^{\prime}$ defined by eq 6 are identical with those defined by eq 3 . If the iso-free volume is valid at $T_{\mathrm{g}}$, that is, $(\partial \tilde{V} / T)_{T_{\mathrm{g}}}=0$, then we have, from eq 5 ,

$$
\left(\partial T_{\mathrm{g}} / \partial P\right)=\Delta \beta / \Delta \alpha \quad \text { (iso-free volume) }
$$

If the iso-configurational entropy (iso- $S^{c}$ ) is satis- 
Table I. Numerical results

\begin{tabular}{ll}
\hline$T_{\mathrm{g}}\left(1^{\circ} \mathrm{C} / 3 \mathrm{~min}, 1 \mathrm{~atm}\right)$ & $97.4,{ }^{\circ} \mathrm{C}$ \\
$V$ at $97.4^{\circ} \mathrm{C}$ & $0.9725, \mathrm{cc} / \mathrm{g}$ \\
$\Delta \alpha$ & $3.1_{2} \times 10^{-4}, \mathrm{~K}^{-1}$ \\
$\Delta \beta$ & $2.28 \times 10^{-5},\left(\mathrm{~kg} \mathrm{~cm}^{-2}\right)^{-1}$ \\
$\Delta C_{p}$ & $0.077, \mathrm{cal} / \mathrm{g} \mathrm{K}$ \\
$\alpha^{\prime}=-\left(\partial \ln V_{\mathrm{s}} / \partial T_{\mathrm{g}}\right)$ & $3.3 \times 10^{-4}, \mathrm{~K}^{-1}$ \\
$\beta^{\prime}=-\left(\partial \ln V_{\mathrm{s}} / \partial P_{\mathrm{g}}\right)$ & $1.0_{5} \times 10^{-5},\left(\mathrm{~kg} \mathrm{~cm}^{-2}\right)^{-1}$ \\
$\left(\partial T_{\mathrm{g}} / \partial P\right)$ & $3.2 \times 10^{-2}, \mathrm{~K} /\left(\mathrm{kg} \mathrm{cm}^{-2}\right)$ \\
$T V \Delta \alpha / \Delta C_{p}$ & $3.4 \times 10^{-2}, \mathrm{~K} /\left(\mathrm{kg} \mathrm{cm}^{-2}\right)$ \\
$\Delta \beta /\left(\Delta \alpha+\alpha^{\prime}\right)$ & $3.6 \times 10^{-2}, \mathrm{~K} /\left(\mathrm{kg} \mathrm{cm}^{-2}\right)$ \\
$\left(\Delta \beta-\beta^{\prime}\right) / \Delta \alpha$ & $3.9 \times 10^{-2}, \mathrm{~K} /\left(\mathrm{kg} \mathrm{cm}^{-2}\right)$ \\
$\Delta \beta / \Delta \alpha$ & $7.3 \times 10^{-2}, \mathrm{~K} /\left(\mathrm{kg} \mathrm{cm}^{-2}\right)$ \\
\hline
\end{tabular}

factory at $T_{\mathrm{g}}$, that is, $(\partial S / \partial T)_{T_{\mathrm{g}}}=0$, then we obtain, from eq 4 and 5 ,

$$
\left(\frac{\partial T_{\mathrm{g}}}{\partial P}\right)=\frac{T V \Delta \alpha}{\Delta C_{p}}=\frac{\Delta \beta}{\Delta \alpha+\alpha^{\prime}}=\frac{\Delta \beta-\beta^{\prime}}{\Delta \alpha}
$$

The eq 8 gives quantitative relations between $\left(\partial T_{\mathrm{g}} / \partial P\right)$ and the magnitude of densification. It must be noticed here that the iso- $S^{\text {e }}$ is equivalent to iso-configurational energy under low pressure. ${ }^{6}$

Results obtained in the present work are sumsarized in Table I. From these results we can conclude within experimental precision that

$$
\left(\frac{\partial T_{\mathrm{g}}}{\partial P}\right) \cong \frac{T V \Delta \alpha}{\Delta C_{p}} \cong \frac{\Delta \beta}{\Delta \alpha+\alpha^{\prime}} \cong \frac{\Delta \beta-\beta^{\prime}}{\Delta \alpha}<\frac{\Delta \beta}{\Delta \alpha}
$$

These results show that not iso-free volume but iso-configurational energy or entropy is valid at $T_{\mathrm{g}}$ and is consistent with that fact, according to the theory, ${ }^{6}$ that heats of solution of densified glasses are similar, on which we will show experimental results supporting the theory in the next paper.
According to Nose's theory, the, specific heat change at $T_{\mathrm{g}}$ arising from intersegmental interactions, $\Delta C_{p}$ inter and that associated with intrasegmental ones, $\Delta C_{p}$ intra are expressed by

$$
\begin{aligned}
\Delta C_{p}{ }^{\text {inter }} & =\frac{T V(\Delta \alpha)^{2}}{\Delta \beta} \\
\Delta C_{p}^{\text {intra }} & =\Delta C_{p}-\frac{T V(\Delta \alpha)^{2}}{\Delta \beta}
\end{aligned}
$$

Using the data shown in Table I, we obtain $\Delta C_{p}{ }^{\text {inter }}=0.036 \mathrm{cal} / \mathrm{g} \mathrm{K}$ and $\Delta C_{p}{ }^{\text {intra }}=0.041 \mathrm{cal} /$ $\mathrm{gK}$, which will be also compared with the values from heat of solution in the next paper.

\section{REFERENCES}

1. F. E. Karasz, H. E. Bair, and J. M. O'Reilly, J. Phys. Chem., 69, 2657, (1965).

2. G. Gee, Polymer, 7, 177, (1966).

3. K. H. Hellwedge, W. Knappe, and P. Lehman, Kolloid-Z. Z. Polym., 183, 110 (1962).

4. J. M. O'Reilly, "Effect of Pressure on Amorphous Polymers" in Modern Aspects of the Vitreous State, J. D. Mackenzie Ed., Butterworths Scientific Publications Ltd., London, 1964, p 59.

5. N. I. Shishkin, Soviet Physics, Solid State, 2,, 322 (1960).

6. T. Nose, Polymer J., 2, 445 (1971); see also T. Nose and T. Hata, "Proceedings of the 5th International Congress of Rheology, University of Tokyo Press, Tokyo, 3, 215, 1970.

7. M. Goldstein, J. Chem. Phys., 39, 3369, (1963).

8. A. Goldberg, W. Hohenstein, and H. Mark, J. Polym. Sci., 2, 503, 1947.

9. M. J. O'Neill, Anal. Chem., 38, 1331, (1966).

10. D. C. Ginnings and G. T. Furukawa, J. Amer. Chem. Soc., 75, 522, (1953). 